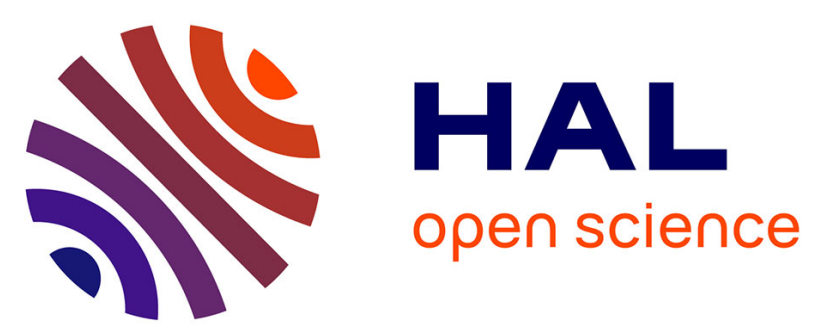

\title{
Effect of projectile nose shape on ballistic resistance of interstitial-free steel sheets
}

K. M. Kpenyigba, T. Jankowiak, A. Rusinek, Raphaël Pesci, Biao Wang

\section{To cite this version:}

K. M. Kpenyigba, T. Jankowiak, A. Rusinek, Raphaël Pesci, Biao Wang. Effect of projectile nose shape on ballistic resistance of interstitial-free steel sheets. International Journal of Impact Engineering, 2015, 79, pp.83-94. 10.1016/j.ijimpeng.2014.10.007 . hal-01166247

\section{HAL Id: hal-01166247 \\ https://hal.science/hal-01166247}

Submitted on 20 Jun 2017

HAL is a multi-disciplinary open access archive for the deposit and dissemination of scientific research documents, whether they are published or not. The documents may come from teaching and research institutions in France or abroad, or from public or private research centers.
L'archive ouverte pluridisciplinaire HAL, est destinée au dépôt et à la diffusion de documents scientifiques de niveau recherche, publiés ou non, émanant des établissements d'enseignement et de recherche français ou étrangers, des laboratoires publics ou privés. 


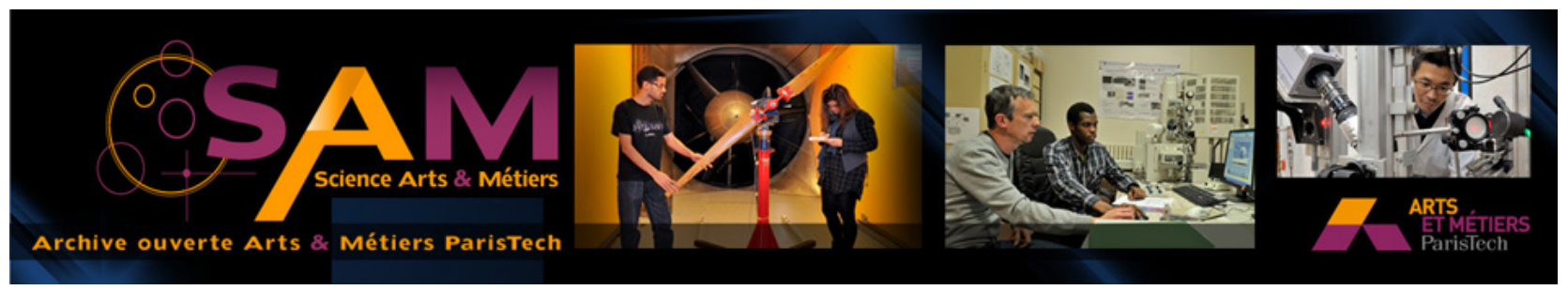

Science Arts \& Métiers (SAM)

is an open access repository that collects the work of Arts et Métiers ParisTech researchers and makes it freely available over the web where possible.

This is an author-deposited version published in: http://sam.ensam.eu

Handle ID: .http://hdl.handle.net/10985/9614

\section{To cite this version :}

K. M. KPENYIGBA, Tomasz JANKOWIAK, Alexis RUSINEK, Raphaël PESCI, Bin WANG - Effect of projectile nose shape on ballistic resistance of interstitial-free steel sheets - International Journal of Impact Engineering - Vol. 79, p.83-94 - 2015 


\title{
Effect of projectile nose shape on ballistic resistance of interstitial-free steel sheets
}

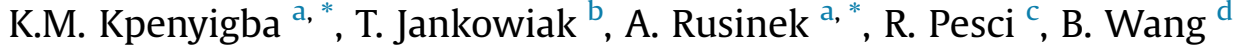 \\ a National Engineering School of Metz, Laboratory of Mechanics, Biomechanics, Polymers and Structures, 1 route d'Ars Laquenexy cs 65820, \\ 57078 Metz Cedex 3, France \\ ${ }^{\mathrm{b}}$ Institute of Structural Engineering, Poznan University of Technology, Piotrowo 5, 60-965 Poznan, Poland \\ ${ }^{\text {c }}$ ENSAM-Arts et Métiers ParisTech CER of Metz, LEM3 UMR CNRS 7239, 4 rue Augustin Fresnel, 57078 Metz Cedex 3, France \\ d School of Engineering and Design, Brunel University, Uxbridge UB8 3PH, UK
}

\begin{abstract}
In this paper an experimental and numerical work is reported concerning the process of perforation of thin steel plates using different projectile nose shapes. The main goal is to analyze how the projectile shape may change the ballistic properties of materials. A wide range of impact velocities from 35 to $180 \mathrm{~m} / \mathrm{s}$ has been covered during the tests. All the projectiles were $13 \mathrm{~mm}$ in diameter and the targets were $1 \mathrm{~mm}$ thick, as such the projectile can be regarded as rigid and the target sheets were of interstitialfree (IF) steel. The mass ratio (projectile mass/steel sheet mass) and the ratio between the span of the steel sheet and the diameter of the projectile were kept constant, equal to 0.38 and 3.85 respectively. To define the thermoviscoplastic behavior of the target material, the Rusinek-Klepaczko (RK) constitutive model [1] was used. The complete identification of the material constants was done based on a rigorous material characterization. Numerical simulations of some experimental tests were carried out using a non-linear finite element code ABAQUS/Explicit. It was found that the numerical models are able to describe the physical mechanisms in the perforation process with a good accuracy.
\end{abstract}

\section{Introduction}

Structural impact has been studied for a long time, and such a problem is known to be complex, both from experimental, analytical and numerical points of view. The most important parameters affecting the ballistic capacity of a target plate are the projectile (size, shape, density and hardness), the target plate (hardness/strength, ductility, microstructure and thickness) and the actual impact conditions (such as impact velocity and projectile incidence angle). This paper concentrates on the ballistic capacity of targets, with the varying factors will being the nose shape of the projectile and the normal impact velocity.

The nose shape of hard projectiles has a strong influence on the failure mode and the ballistic limit of a target [2-4]. Corran et al. [5] investigated the effect of projectile mass, nose shape and hardness on the penetration of steel and aluminum alloy plates. Blunt and conical projectiles of $12.5 \mathrm{~mm}$ diameter were impacted on plates $1.3-5.9 \mathrm{~mm}$ thick and considering a velocity ranging from 50 to
$250 \mathrm{~m} / \mathrm{s}$. The mass of the projectile varied from 15 to $100 \mathrm{~g}$. They observed that the ballistic limit of the plate changes with projectile mass and nose shape. Goldsmith et al. [6] experimentally investigated normal impact of cylindro-conical and blunt projectiles into aluminum and steel sheet targets. The thickness of aluminum targets varied from $1.78 \mathrm{~mm}$ to $25.4 \mathrm{~mm}$ and that of steel plates varies from $1 \mathrm{~mm}$ to $19 \mathrm{~mm}$. It was observed that the nose shape of projectile had insignificant effect on the ballistic limit. Ipson and Recht [7] found that conical projectiles penetrated the target in a less efficient way than blunt projectiles when the target thickness was moderate. However, for a thin and thick target, an opposite trend was observed by the authors. This is due to the different modes of failure involved. Experiments investigation carried out by Zukas et al. [8] showed that the projectile with blunt nose shape has higher ballistic limit velocity. A more recent work done by Kpenyigba et al. [9] on the impact of blunt, conical and hemispherical shape projectiles on $1 \mathrm{~mm}$ thick mild steel sheets indicated that the ballistic limit is higher for hemispherical shape projectile, followed by conical and blunt respectively. The authors also showed that the blunt projectile failed the target by plug ejection due to a process of high speed shearing, the conical projectile caused failure by petaling due to a process of piercing and the hemispherical shape 
Table 1

Chemical composition of the IF steel (weight\%).

\begin{tabular}{|c|c|c|c|c|c|c|c|c|c|c|}
\hline C & $S$ & Mn & $\mathrm{P}$ & $\mathrm{Si}$ & $\mathrm{Cu}$ & $\mathrm{Ni}$ & $\mathrm{Cr}$ & $\mathrm{Al}$ & V & Sn \\
\hline 0.0018 & 0.007 & 0.095 & 0.009 & 0.006 & 0.026 & 0.015 & 0.023 & 0,06 & 0.001 & 0.003 \\
\hline
\end{tabular}

projectile led to radial hole expansion inducing necking and radial cracks. Backman and Goldsmith [3] concluded that blunt shape projectiles caused failure through plugging, wedge projectiles by ductile hole enlargement and sharp nosed projectiles by petaling. Borvik et al. $[2,10]$ studied experimentally and numerically the perforation of $12 \mathrm{~mm}$ thick Weldox $460 \mathrm{E}$ steel plates and showed that the blunt projectiles caused failure by plugging, which was dominated by shear banding, while hemispherical and conical projectiles penetrated the target mainly by pushing the material in front of the projectile aside. Gupta et al. [11] reported that the failure in thin ductile targets occurred through shear plugging by blunt projectiles, petal forming by ogive nosed projectiles and tensile stretching by hemispherical projectiles. The high velocity impacts of the high strength projectiles into monolith $6 \mathrm{~mm}$ and sandwiched plates $2 \times 6 \mathrm{~mm}$ of 45 and of Q235 steels were investigated by Deng et al. [12]. The results present the influence of the nose shape (ogival or blunt) on the ballistic resistance of the structure. The authors also presented the influence of the order of the material in sandwiched structures [12]. The available experimental and numerical investigations on the perforation and penetration of ductile metal targets by rigid projectiles are mostly restricted to a few specific nose shapes such as hemispherical, conical, ogival and blunt. In this work, some experimental tests were carried out on thin IF steel targets in order to study in detail the effect of projectile nose shape in structural impact at subordnance velocities. Moreover, an additional investigation was made to study the influence of a double-nosed stepped cylindrical projectile. Based on the experimental results, the ballistic curves were plotted for each projectile shape. Numerical simulations using a finite element code ABAQUS/Explicit were performed and the results obtained allow prediction properly the complete process of perforation.

\section{Experimental material behavior description}

The material studied is a $1 \mathrm{~mm}$ thick sheet of a deep-drawing quality IF steel. The IF steel was developed to obtain an optimized compromise between the mechanical strength and the formability due to specific metallurgy without interstitial elements (interstitial-free). It is mainly used for structural components subject to fatigue impact loading. The chemical composition of the material (in weight\%) is given in Table 1. This steel has a ferritic structure with more or less equiaxial grains about $25 \mu \mathrm{m}$ in diameter.

Quasi-static tensile tests were conducted on a universal test machine (eg. Instron) and dynamic tensile tests were performed on a fast servo-hydraulic universal machine (eg. Zwick). A wide range of strain rates was covered at room temperature,

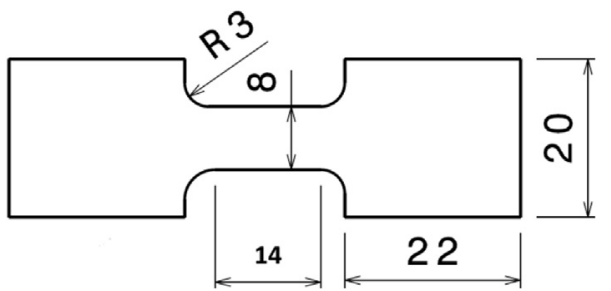

Fig. 1. Geometry and dimensions of the tensile specimens, Rusinek et al [13].
$10^{-4} \mathrm{~s}^{-1} \leq \dot{\varepsilon} \leq 250 \mathrm{~s}^{-1}$. The geometry and dimensions of the tensile specimens used in the characterization are given in Fig. 1. The thickness of the specimens is $t=1 \mathrm{~mm}$. To analyze possible material anisotropy in the plane of the steel sheet, tension tests were performed in two directions additional to the rolling direction: $\varphi_{1}=45^{\circ}$ and $\varphi_{2}=90^{\circ}$.

Rusinek et al. $[13,14]$ showed that the dimensions of the tensile specimens (Fig. 1) are optimum, which allows to achieve a proper level of stress coupled with sufficient ductility. The authors highlighted that this specimen design allows to avoid geometrical disturbances that frequently take place when small samples are used to reach very high strain rates during testing. For all tests performed, the true stress-strain curves were obtained up to incipient necking.

The curves in Fig. 2 show that the effect of rolling direction is not insignificant on the macroscopic behavior of the steel sheet. According to this result coupled to the microscopic observation, the isotropy is assumed in the description of the material behavior.

The true stress-strain curves at different strain rates are shown in Fig. 3. The first observation is an increase of the flow stress and the yield stress as the strain rate increase. For a high strain rate, the curves change shapes particularly by the presence of a thermal softening due to local temperature elevation during the tests. The loading time is short and the temperature does not have time to dissipate through the specimen. During these tests, necking which diffuses into the specimen to cause the final failure occurs much earlier than for tests at low strain rates. For the strain rate of $\dot{\varepsilon}=250 \mathrm{~s}^{-1}$, the macroscopic material behavior is substantially different at the beginning of loading. A significant peak stress (450 MPa) is observed. This peak is related to the microstructure of the material and particularly, to the dislocation density. Similar behavior has been reported in Refs. [15,16] and in Ref. [17] where the level of carbon on the macroscopic behavior has been studied. It was observed that a decrease of the carbon level helps to dissipate the peak stress at the beginning of loading. There is a relatively high

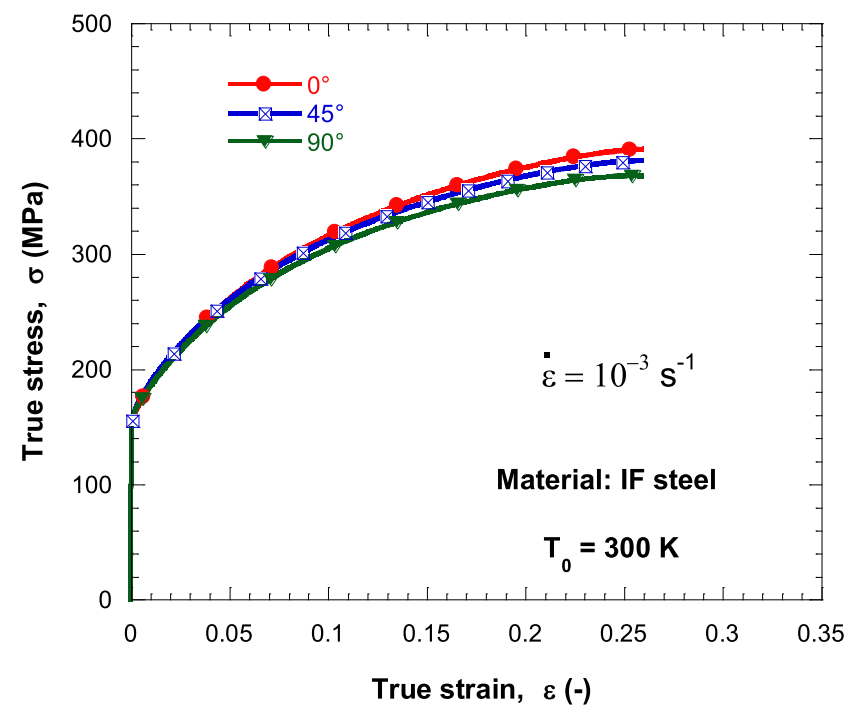

Fig. 2. Comparison of quasi-static tensile flow curves in three directions: $0^{\circ}$ as well as $45^{\circ}$ and $90^{\circ}$ 


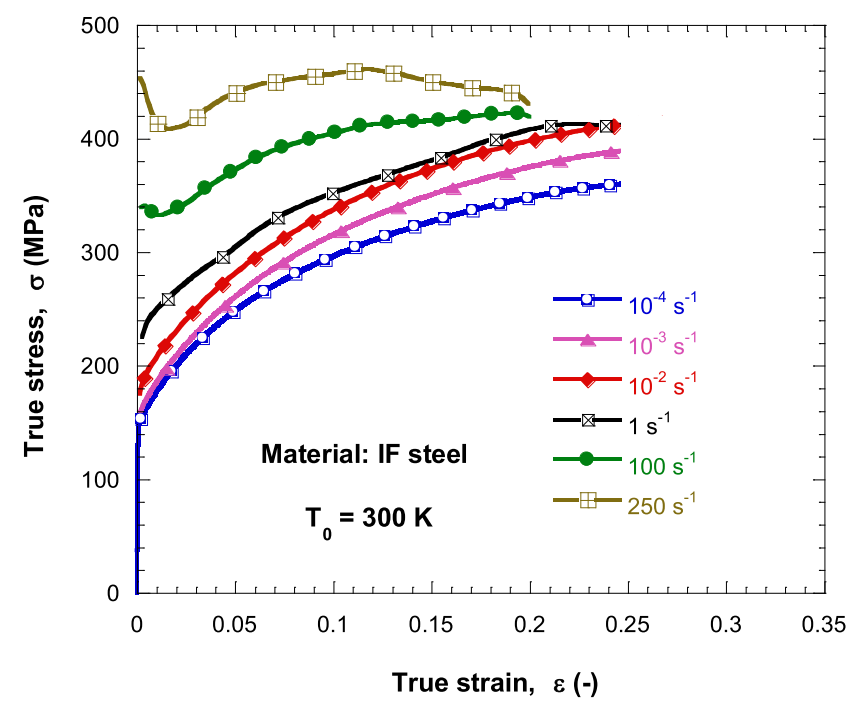

Fig. 3. Comparison of true stress versus true strain curves of IF steel at different strain rates.

hardening for quasi-static solicitation and which decreases when the strain rate increases. The IF steel has a positive sensitivity to strain rate as most materials with bcc crystallographic structure. This sensitivity to the strain rate of the flow stress is defined by:

$\psi=\left.\frac{\partial \sigma}{\partial \log \dot{\varepsilon}}\right|_{\varepsilon, T}$

It can be observed that the strain rate sensitivity at room temperature is not constant, Fig. 4. Three characteristic regions with different sensitivity to the strain rate were reported by Campbell and Ferguson [18].

In the next section, the constitutive relation use to describe the material behavior, the comparison between the experimental data and analytical modeling are reported and discussed.

\section{Thermoviscoplastic modeling of material behavior}

Several constitutive relations are available in the literature and used in finite element code to predict the distribution of plastic

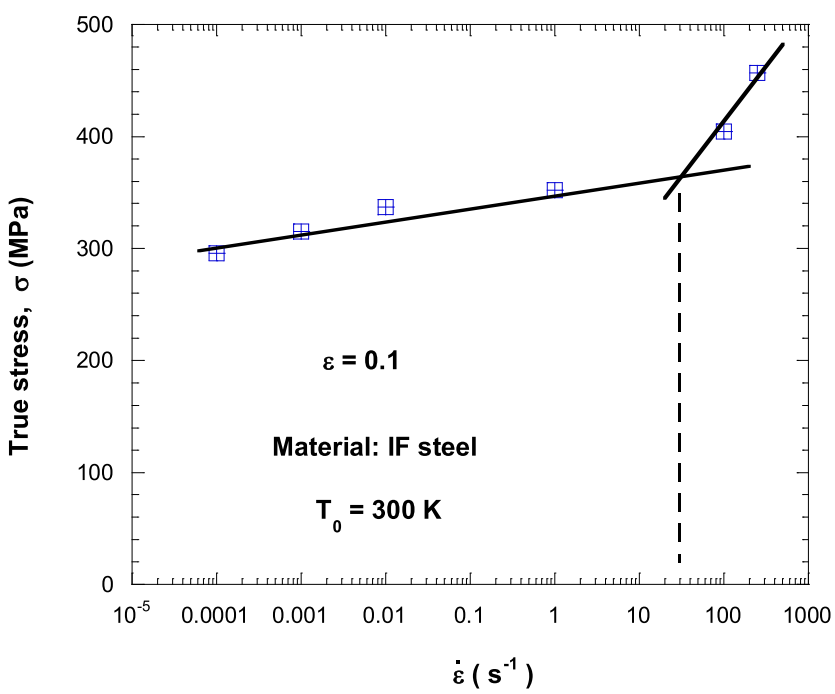

Fig. 4. Flow stress evolution as a function of the strain rate at room temperature for a strain level imposed of $\varepsilon=0.1$. deformation and the failure in structures impact. Some of them are limited to perfectly plastic approximations with some viscoplasticity. More sophisticated versions, such as those that take into account the effect of the strain rate, temperature and hardening on the flow stress are also available nowadays. In this work, the RK constitutive relation is used [1]. The model is partially based on the theory of dislocations and its phenomenological description is based on the additive decomposition of the total stress [19]:

$\sigma(\varepsilon, \dot{\varepsilon}, T)=\frac{E(T)}{E_{0}}\left[\sigma_{\mu}(\varepsilon, \dot{\varepsilon}, T)+\sigma^{*}(\dot{\varepsilon}, T)\right]$

where each term of the previous expression, Eq. (2), is defined below.

The multiplicative factor $E(T) / E_{0}$ defines Young's modulus evolution with temperature [20]: We added with $T>0$ for Eq. (3) and (5)

$E(T)=E_{0}\left(1-\frac{T}{T_{m}} \exp \left[\theta^{*}\left(1-\frac{T_{m}}{T}\right)\right]\right)$ with $T>0$

where $E_{0}, T_{m}$ and $\theta^{*}$ are respectively the Young's modulus at $T=0 \mathrm{~K}$, the melting temperature and the characteristic homologous temperature. This expression allows to define the material thermal softening depending on its crystal lattice [21]. In the case of bcc metals like steel $\theta^{*} \approx 0.6$.

The internal component of the total stress called the athermal stress is defined by the following equation:

$\sigma_{\mu}(\varepsilon, \dot{\varepsilon}, T)=B(\dot{\varepsilon}, T)\left(\varepsilon_{0}+\varepsilon\right)^{n(\dot{\varepsilon}, T)}$

where, $B(\dot{\varepsilon}, T)$ is the modulus of plasticity, $n(\dot{\varepsilon}, T)$ the hardening coefficient $(B(\dot{\varepsilon}, T)$ and $n(\dot{\varepsilon}, T)$ depend on the strain rate and temperature) and $\varepsilon_{0}$ is the value of strain corresponding to the yield stress at a given strain rate and temperature.

The authors propose the following formulations to describe the modulus of plasticity and strain hardening exponent:

$B(\dot{\varepsilon}, T)=B_{0}\left(\left(\frac{T}{T_{m}}\right) \log \left(\frac{\dot{\varepsilon}_{\max }}{\dot{\varepsilon}}\right)\right)^{-\nu}$ with $T>0$

$n(\dot{\varepsilon}, T)=n_{0}\left\langle 1-D_{2}\left(\frac{T}{T_{m}}\right) \log \left(\frac{\dot{\varepsilon}}{\dot{\varepsilon}_{\text {min }}}\right)\right\rangle$

where $B_{0}$ is the material constant, $\nu$ proportional to temperature sensitivity, $n_{0}$ the strain hardening exponent at $T=0 K, D_{2}$ the material constant, $\dot{\varepsilon}_{\text {min }}$ the lower strain rate limit of the model and $\dot{\varepsilon}_{\max }$ the maximum strain rate level accepted for a particular material. The Macaulay operator is defined as follows: $\langle\cdot\rangle=$. if $\cdot>0$, otherwise $\langle\cdot\rangle=0$.

The effective stress $\sigma^{*}(\dot{\varepsilon}, T)$ is the flow stress component which defines the rate dependent interactions with short range obstacles. It denotes the rate controlling deformation mechanism from thermal activation. At temperatures $T>0 \mathrm{~K}$, thermal activation assists the applied stress.

The theory of thermodynamics and kinetics of slip [22] is founded on a set of equations which relate activation energy $\Delta G$, mechanical threshold stress $\sigma$ (MTS), applied stress $\sigma$, strain rate $\dot{\varepsilon}$, temperature $T$ and determined physical material parameters. Based on such understanding of the material behavior, Rusinek and Klepaczko [1] derived the following expression, Eq. (7). This formulation gathers the reciprocity between strain rate and temperature by means of an Arrhenius type equation: 
Table 2

Constants used to describe the mechanical behavior based on the RK model, Eq. (2), and to describe temperature increase Eq. (8).

\begin{tabular}{|c|c|c|c|c|c|c|c|c|c|c|}
\hline & $D_{1}(-)$ & $D_{2}(-)$ & $n_{0}(-)$ & $B_{0}(\mathrm{MPa})$ & $\dot{\varepsilon}_{\min }\left(\mathrm{s}^{-1}\right)$ & $\dot{\varepsilon}_{\max }\left(\mathrm{s}^{-1}\right)$ & $\nu(-)$ & $\varepsilon_{0}(-)$ & $m^{*}(-)$ & $\sigma_{0}^{*}(\mathrm{MPa})$ \\
\hline Acier IF & 0.48 & 0.79 & 0.35 & 636.9 & $10^{-4}$ & $10^{7}$ & 0.25 & 0.018 & 1.51 & 313.24 \\
\hline$\beta(-)$ & & & & & $\left.\mathrm{Kg}^{-1} \mathrm{~K}^{-1}\right)$ & & & & & $\rho\left(\mathrm{kg} \mathrm{m}^{-3}\right)$ \\
\hline 0.9 & & & & & & & & & & 7800 \\
\hline
\end{tabular}

$\sigma^{*}(\dot{\varepsilon}, T)=\sigma_{0}^{*}\left\langle 1-D_{1}\left(\frac{T}{T_{m}}\right) \log \left(\frac{\dot{\varepsilon}_{\text {max }}}{\dot{\varepsilon}}\right)\right\rangle m^{*}$

where $\sigma_{0}^{*}$ is the effective stress at $T=0 K, D_{1}$ the material constant and $m^{*}$ the constant defining the reciprocity strain ratetemperature [19].

In the case of adiabatic conditions of deformation the constitutive relation is combined with the energy balance principle, Eq. (8). Such relation allows for an approximation of the thermal softening of the material by means of the adiabatic heating.

$T=T_{0}+\Delta T=T_{0}+\frac{\beta}{\rho C_{p}} \int_{\varepsilon_{e}}^{\varepsilon_{f}} \sigma \mathrm{d} \varepsilon$

where $\beta$ is the Quinney-Taylor coefficient, $\rho$ the density of the sheet steel, $C_{p}$ the specific heat and $\varepsilon_{f}$ the failure strain level, Table 2 .

Subsequently a straightforward method was proposed by Rusinek and Klepaczko [1,23] for the model calibration. It allows defining the model parameters step by step. Contrary to other constitutive descriptions, the procedure does not involve a global fitting. It must be noticed that the constants are defined using physical assumptions [1,23].

The main steps necessary for defining the model parameters are:

$\checkmark$ It is assumed that at low strain rate $\dot{\varepsilon} \leq 0.001 \mathrm{~s}^{-1}$, the stress contribution due to thermal activation is reduced and in this case the following relation is imposed, Eq. (9). Thus, it is possible to define the constant $D_{1}$ depending on the melting temperature $T_{m}$.

$\left\{\begin{array}{c}\left.\sigma^{*}(\dot{\varepsilon}, T)\right|_{300 \mathrm{~K}, 0.001 \mathrm{~S}^{-1}}=0 \\ D_{1}=\left[\left(\frac{300}{T_{m}}\right) \log \left(\frac{\dot{\varepsilon}_{\max }}{0.001}\right)\right]^{-1}\end{array}\right.$

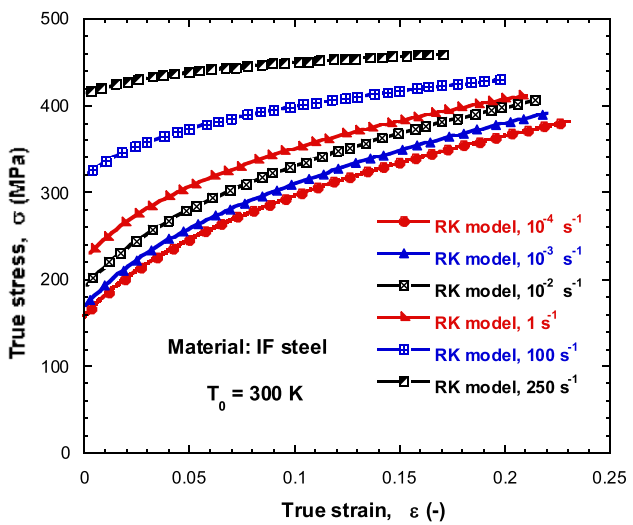

a) $\checkmark$ Therefore, at room temperature and under quasi-static loading the contribution of the thermal stress component to the total stress is zero. The overall stress level is defined by Eq. (10). Fitting this equation to experiment results, a first estimation of $B$ and $n$ can be found.

$\left\{\begin{array}{c}\sigma(\varepsilon, 0.001,300)=\frac{E(300)}{E_{0}}\left[B\left(\varepsilon_{0}+\varepsilon\right)^{n}+0\right] \\ B, n \text { first approximation }\end{array}\right.$

Next, it is assumed that the increase of the flow stress caused by the strain rate augment is due to the thermal stress $\sigma^{*}(\dot{\varepsilon}, T)$.Thus, the stress increase is defined as follows, Eq. (11). Fitting of Eq. (11) to experimental results for an imposed strain level, makes it possible to determine the material constants $\sigma^{*}$ and $\mathrm{m}^{*}$. The strain level should be assumed not more than 0.1 in order to guarantee isothermal condition of deformation. For larger strain values, adiabatic conditions may induce a thermal softening on the material and in such a case a decrease of the strain hardening.

$$
\left\{\begin{array}{c}
\left.\Delta \sigma\right|_{0.001 \mathrm{~S}^{-1} \rightarrow \dot{\varepsilon}} ^{\varepsilon}=\left.\sigma\right|_{\dot{\varepsilon}} ^{\varepsilon}-\left.\sigma\right|_{0.001 \mathrm{~S}^{-1}} ^{\varepsilon}=\left.\sigma^{*}(\dot{\varepsilon}, T)\right|^{\varepsilon} \\
\sigma_{0}^{*}, m^{*}
\end{array}\right.
$$

$\checkmark$ Finally, combining the complete equation of the total stress (Eq. (2)) with the experimental results and replacing the parameters determined above, it allows to determine the parameters $B(\dot{\varepsilon}, T)$ and $n(\dot{\varepsilon}, T)$ depending on the strain rate and temperature.

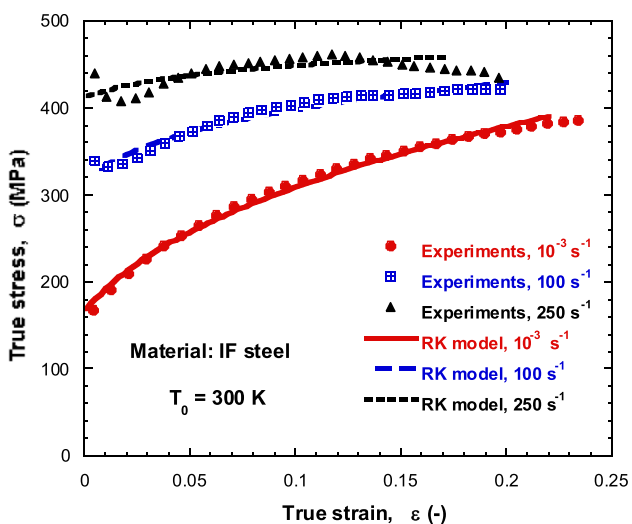

b)

Fig. 5. a) RK model for different strain rates; b) Comparison between RK modeling and experimental data. 


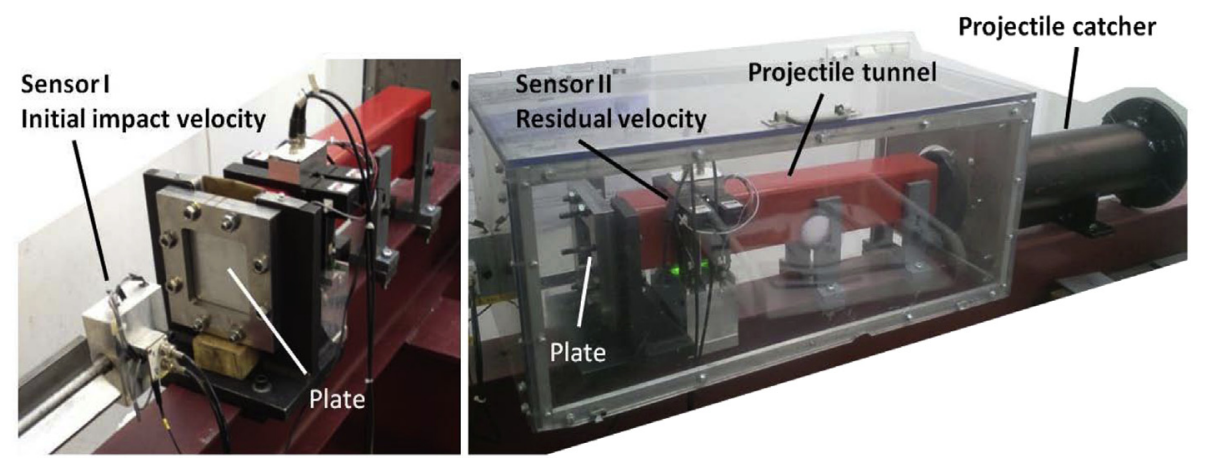

Fig. 6. Experimental device used for impact tests.

The curves from RK modeling are plotted in Fig. 5(a). It is noted that the hardening decreases with the strain rate.

Analytical approximations were compared with experiment results from quasi-static and dynamic loading showing a good agreement as seen in Fig. 5(b). The constants of the model RK determined for the material IF are summarized in Table 2.

\section{Experimental perforation tests}

\subsection{Experimental set-up description}

Ballistic perforation tests have been carried out on $1 \mathrm{~mm}$ thick IF steel targets plates using rigid projectiles with different nose shapes and a pneumatic gas gun. The experimental apparatus used for the realization of ballistic impact tests consist mainly of a gas launcher, Fig. 6, and auxiliary equipments required for the recording and the processing of data provided by the tests: especially the two sensors used to measure the projectile velocity. The first sensor located at the end of the launcher tube allows to measure the initial impact velocity of the projectile and the second sensor just positioned behind the target allows to measure the residual velocity. The complete description of the perforation process is available in Refs. [9,24].

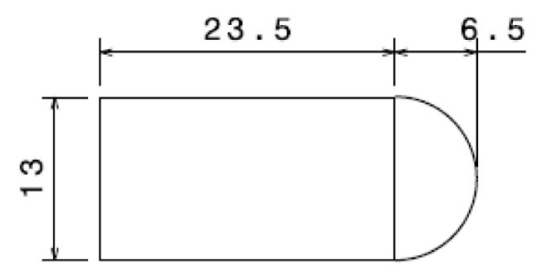

a)

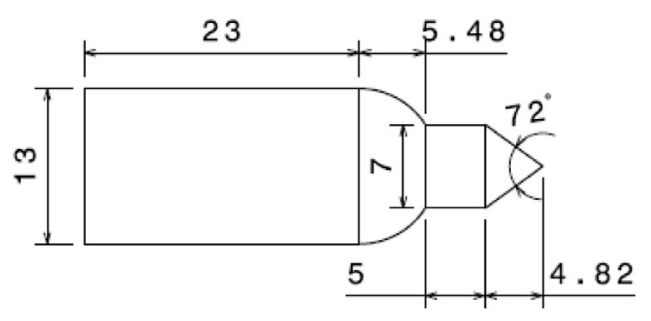

c)
The projectiles used in this study were designated according to their respective nose shape such as conical, hemispherical, hemispherical + conical (projectile A) and hemispherical-conical (projectile B), Fig. 7. They are all machined from Maraging steel with a heat treatment to reach a yield stress of $2 \mathrm{GPa}$. Therefore, the projectile may be assumed as rigid (without mushroom effect) during the process of perforation. For each configuration the projectile mass was kept constant, $m_{p} \approx 30 \mathrm{~g}$, to have the same kinetic energy so that the shape effect can be analyzed. The diameter of all projectile is $\phi_{p}=13 \mathrm{~mm}$.

The dimensions of the square plates used during experiments are given, Fig. 8 . The active part is $100 * \mathrm{~mm}^{2}$, the thickness is $1 \mathrm{~mm}$ and it is embedded on a rigid support allowing the reduction of effect during the test. The plate has been impacted by the projectile in the central zone as shown in Fig. 8. A wide range of initial impact velocities was considered for a complete definition of the ballistic curve of the steel sheet.

\subsection{Experimental results under ballistic impact}

In this part, the influence of the projectile shape on the perforation tests is studied. The ballistic curves $V_{R}-V_{0}$ for projectile are reported on Fig. 9.

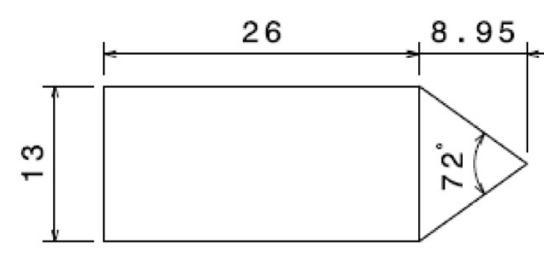

b)

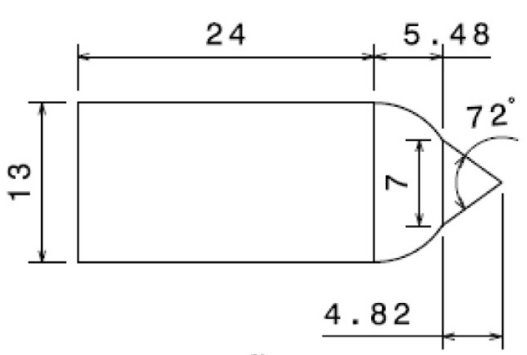

d)

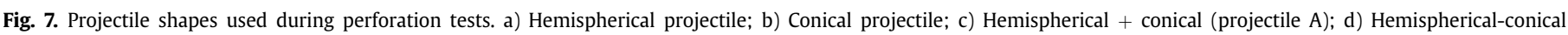
(projectile B). 


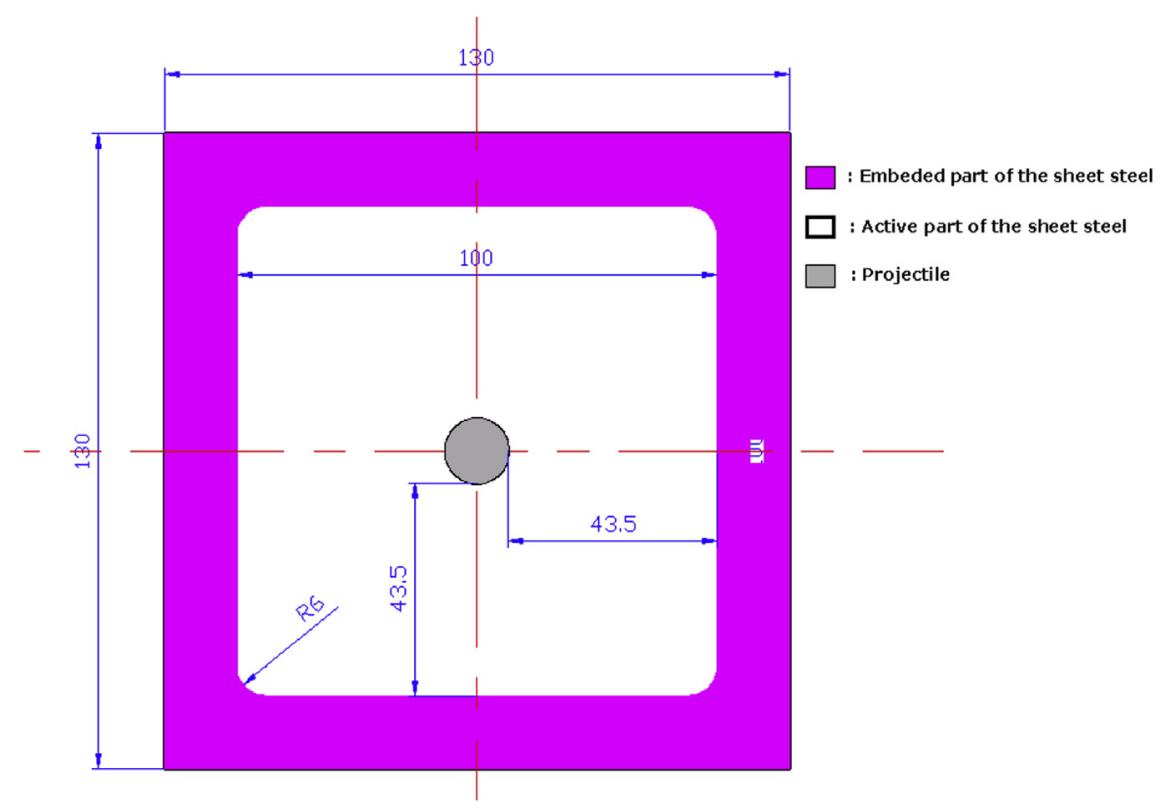

Fig. 8. Geometry of the steel plates used during perforation tests, thickness $1 \mathrm{~mm}$.

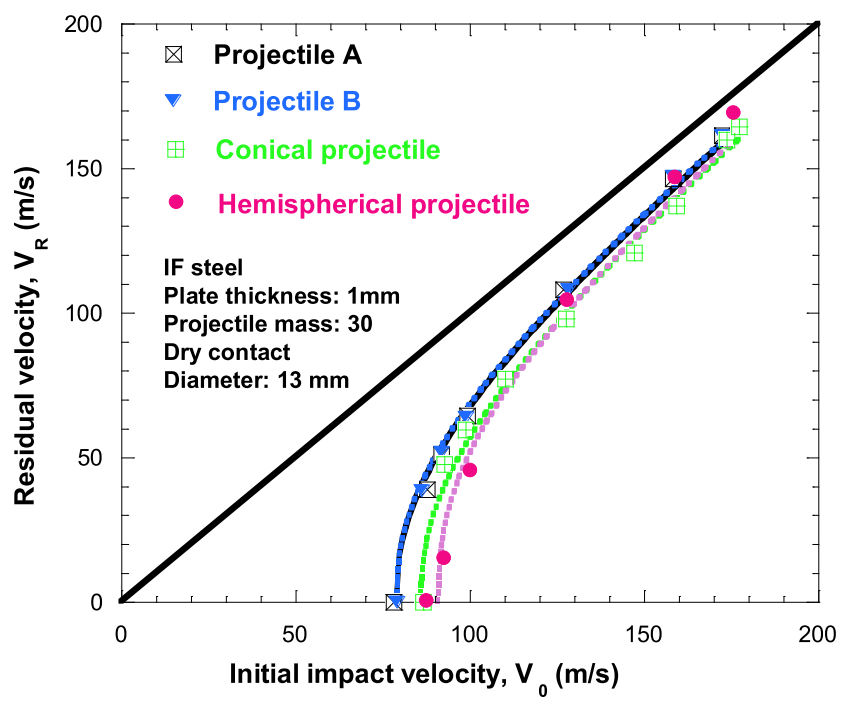

Fig. 9. Experimental results in terms of residual velocities for different projectiles shapes.

The conical and hemispherical shapes are generally used to analyze the process of failure. The first one induces a failure mode by petaling and the second one a plug ejection due to circumferential necking. A previous analysis has been published by Kpenyigba et al. [9]. In addition to these two shapes, projectiles coupling hemispherical and conical design (projectile A and B) have been used. The conical end allows to perforate the plate more easily by a process of piercing. The projectile damages the target plate by radial necking and petal forming. The failure is dominated by the process of high-speed piercing as in the case of a conical projectile.

Table 3

Constants used to fit experiments based on Eq. (12).

\begin{tabular}{llll}
\hline Conical & Hemispherical & A & B \\
\hline$\kappa=2.21$ & $\kappa=2.39$ & $\kappa=2.25$ & $\kappa=2.28$ \\
$V_{B}=86.5 \mathrm{~m} / \mathrm{s}$ & $V_{B}=90 \mathrm{~m} / \mathrm{s}$ & $V_{B}=78 \mathrm{~m} / \mathrm{s}$ & $V_{B}=79 \mathrm{~m} / \mathrm{s}$ \\
\hline
\end{tabular}

For projectile B, a mix of failure modes is observed: petaling and radial cracks.

It is observed, based on the experimental results that the conical projectile shape allows to decrease the ballistic limit $V_{B}$ of the material considered, Fig. 9, in comparison with the hemispherical projectile. Moreover, keeping the same conical nose angle $\varphi_{p}=72^{\circ}$ coupled to a hemispherical projectile, Fig. 7(c and d), the ballistic limit is lower than $\Delta V_{b}^{\text {Conical }} \approx 6 \mathrm{~m} / \mathrm{s}$ compared to the conical projectile, Fig. 7(b). The difference is close to $\Delta V_{b}^{\text {Hemispherical }} \approx 10 \mathrm{~m} / \mathrm{s}$ between shape $A$ and $B$ and the hemispherical projectile. Using a reduced conical shape projectile nose allows to induce a failure mode by piercing. After that, when a hole is initiated the process of hole enlargement is easier and the velocity of the projectile is less reduced. This mechanism is discussed in details using numerical observations in terms of failure time.

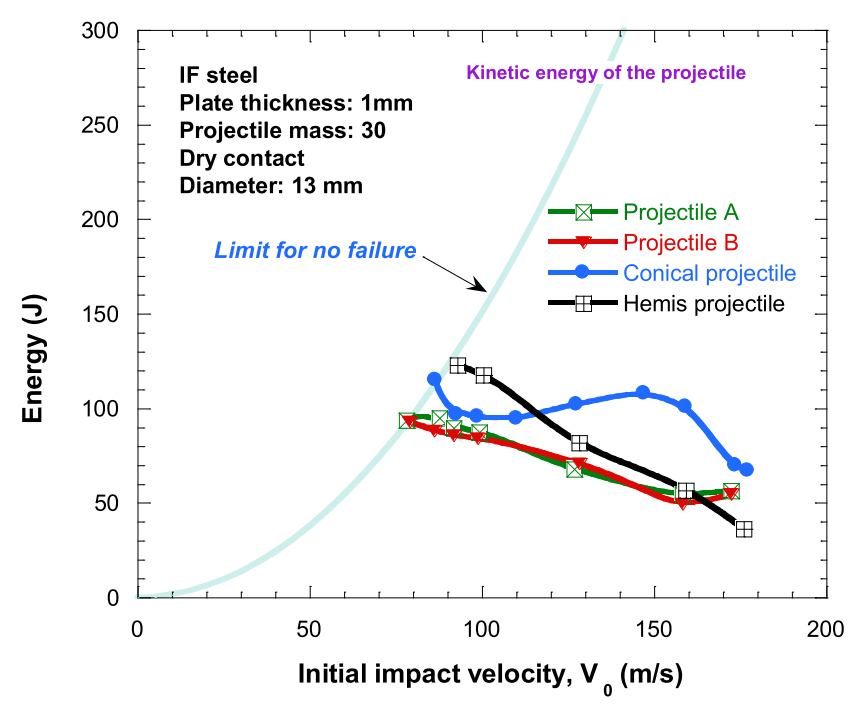

Fig. 10. Experimental results in term of absorbed energy for different projectiles shapes. 


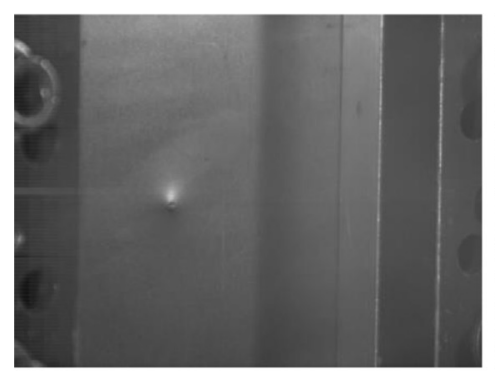

$30 \mu s$-impact

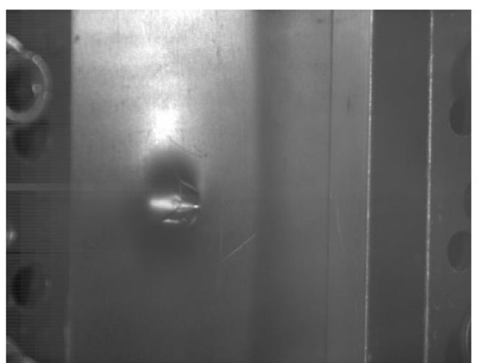

$150 \mu s$ - penetration

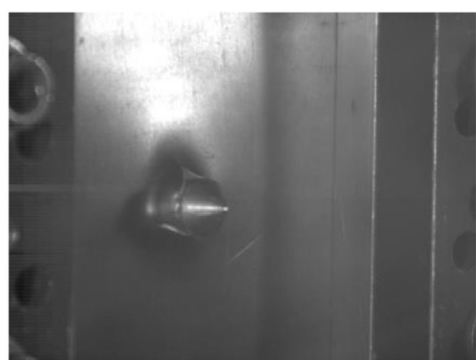

$182 \mu \mathrm{s}$-perforation

Fig. 11. Perforation process steps using a conical projectile, $V_{0}=178 \mathrm{~m} / \mathrm{s}$.

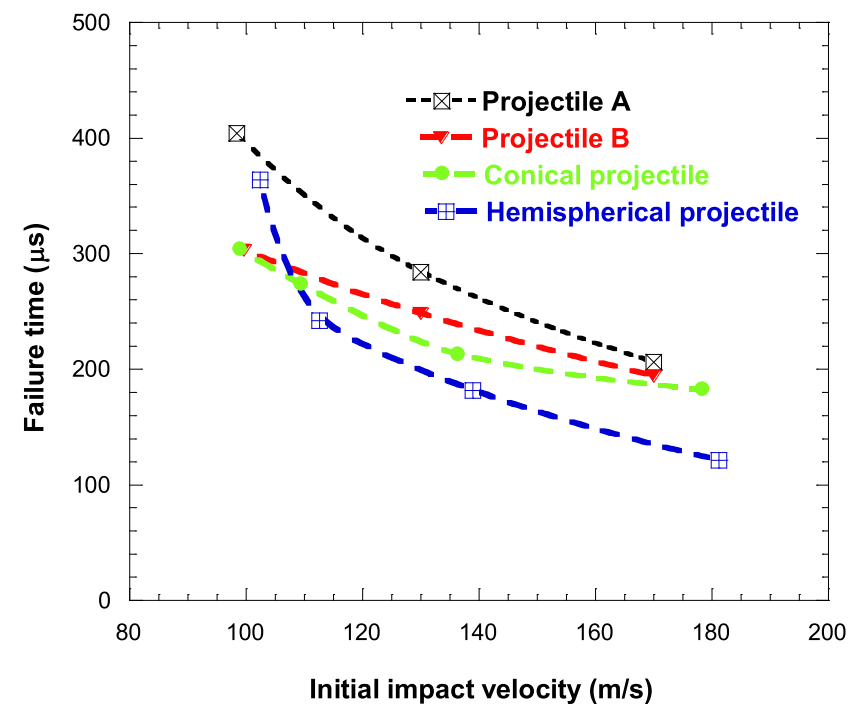

Fig. 12. Failure time depending on the initial impact velocity for different projectiles.
The ballistic curves in general were approximated using the proposed analytical equation of Recht et al. [25] whose formulation for thin plates is as follows: Table 3 .

$V_{R}=\left(V_{0}^{K}-V_{B}^{K}\right)^{1 / \kappa}$

where $V_{B}$ is the ballistic limit and $\kappa$ is a fitting parameter.

The difference between the ballistic curves is greater at the ballistic limit than at high impact velocities $\left(V_{0} \geq 150 \mathrm{~m} / \mathrm{s}\right)$. When the residual velocity $V_{R}$ is higher, the energy absorbed by the plate to perforate is lower, as seen in Fig. 10. During the perforation of the plate, a part of the kinetic energy of the projectile is absorbed by the global deformation of the steel sheet, the localized plastic deformation in the impact zone and the elastic work. The residual kinetic energy is quite simply the residual energy of the projectile after impact. If the impact velocity is lower than the ballistic limit, the energy absorbed by the plate is directly the kinetic energy of the projectile $\left(\left(1 / 2 m_{p} V_{0}^{2}\right)\right)$. The balance of the energy absorbed by the plate during perforation is as follows [26]:

$W_{\text {Plate }}^{\text {Total }}=W_{\text {Plate }}^{K}+W^{E}+W^{P}+W^{F}+W_{\text {Débris }}^{K}=\frac{1}{2} m_{p}\left(V_{0}^{2}-V_{B}^{2}\right)$

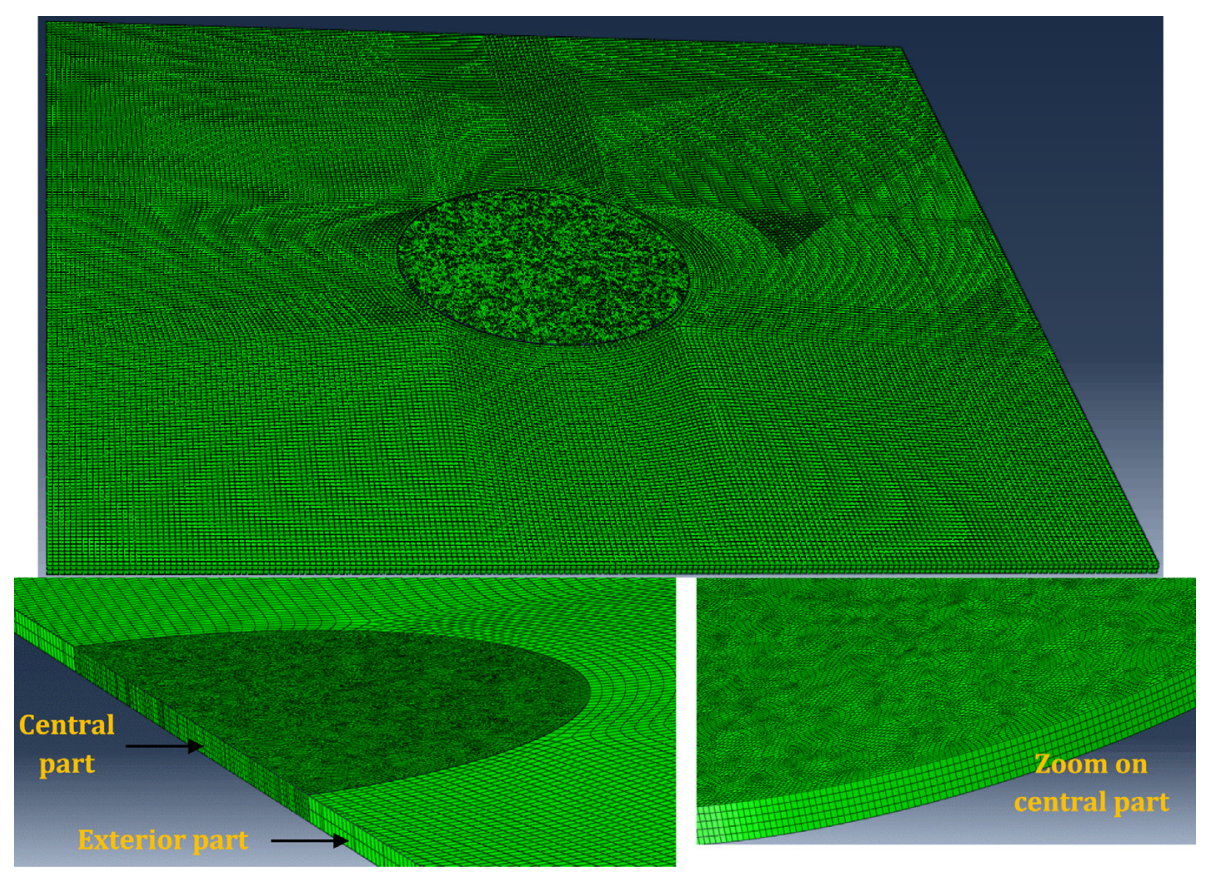

Fig. 13. Numerical model used in this work and mesh density distribution. 
Table 4

Failure strain values used to simulate perforation depending on the projectile shape.

\begin{tabular}{lllll}
\hline & $\begin{array}{l}\text { Projectile } \\
\mathrm{A}\end{array}$ & $\begin{array}{l}\text { Projectile } \\
\mathrm{B}\end{array}$ & $\begin{array}{l}\text { Conical } \\
\text { shape }\end{array}$ & $\begin{array}{l}\text { Hemispherical } \\
\text { shape }\end{array}$ \\
\hline $\begin{array}{c}\text { Failure strain level, } \\
\varepsilon_{f}(-)\end{array}$ & 1.2 & 1.2 & 1.2 & 0.65 \\
Stress triaxiality, $\bar{\eta}$ & $1 / 3$ & $1 / 3$ & $1 / 3$ & $2 / 3$ \\
\hline
\end{tabular}

where $W_{\text {Plate }}^{K}, W^{E}, W^{P}, W^{F}$ and $W_{\text {Debris }}^{K}$ are respectively the energy related to the global deflection of the plate, the elastic deformation energy, the plastic deformation energy, the energy related to the phenomenon of friction and the kinetic energy transferred to the fragments ejected during impact (ejection of plug for example when the hemispherical projectile is used). As shown in Ref. [9], the loss of energy due to the friction effect can be disregarded and the energy transferred to the fragments is minor $\left(W^{F} \approx 0, W_{\text {Débris }}^{K} \approx 0\right)$. The energy balance is then reduced as follows:

$W_{\text {Plate }}^{\text {Total }}=W_{\text {Plate }}^{K}+W^{E}+W^{P}=\frac{1}{2} m_{p}\left(V_{0}^{2}-V_{B}^{2}\right)$

The evolution of $W_{\text {Plate }}^{\text {Total }}$ as a function of $V_{0}$ obtained experimentally for each kind of projectile shape is presented in Fig. 10.

A decrease of the absorbed energy with the impact velocity is generally observed: an increment of impact velocity leads to a fast localization of the deformation and quick failure of the target.

To estimate the time necessary for the projectile to perforate the plate, called failure time, the experimental perforation tests were recorded using a high speed camera Phantom v710. The failure time is defined as the time elapsing between the beginning of the impact and when the nose of the projectile passes completely through the plate, as shown in Fig. 11 (case of a conical projectile).

The experimental results in terms of failure time as a function of initial impact velocity are reported in Fig. 12. For all projectiles studied, the failure time decrease with the impact velocity. The higher is the projectile initial velocity, the faster is the process of perforation.

Apart from the lower speed range, in general, the failure time is lower at the same impact velocity for projectile A, followed by projectile $B$, then the conical and the hemispherical projectiles, respectively.

\section{Numerical model for dynamic perforation}

The impact and perforation tests using a rigid projectile against thin steel sheet were numerically analyzed for the purpose to predict the experimental observation. The finite element code ABAQUS/Explicit was used to simulate the process.

\subsection{Description of the numerical model}

In all simulations, the projectile was modeled as a threedimensional non-deformable rigid body (discrete) with a reference point to affect velocity. The mass and inertia moments were automatically calculated based on the shape, volume and density of the projectile and assigned to its reference point. The target was

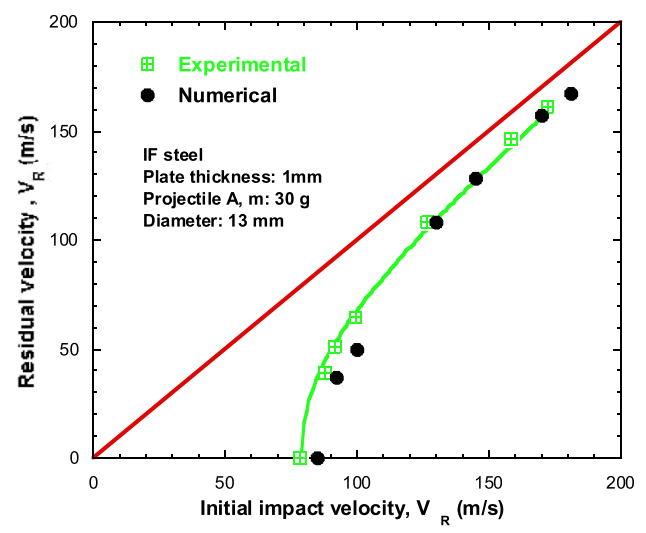

a)

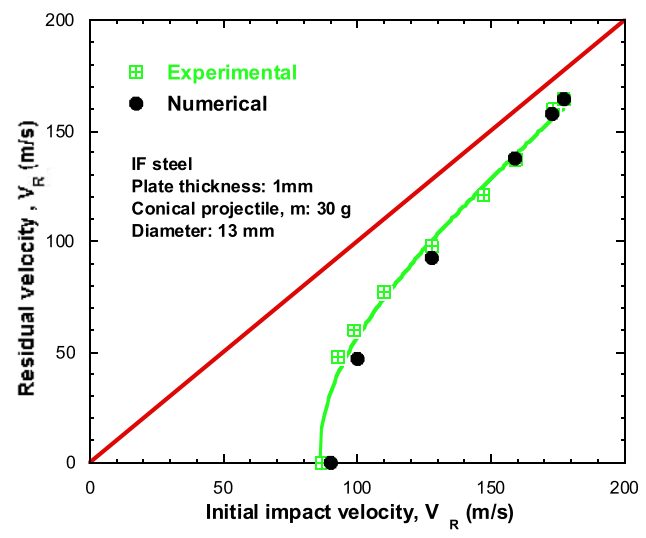

c)

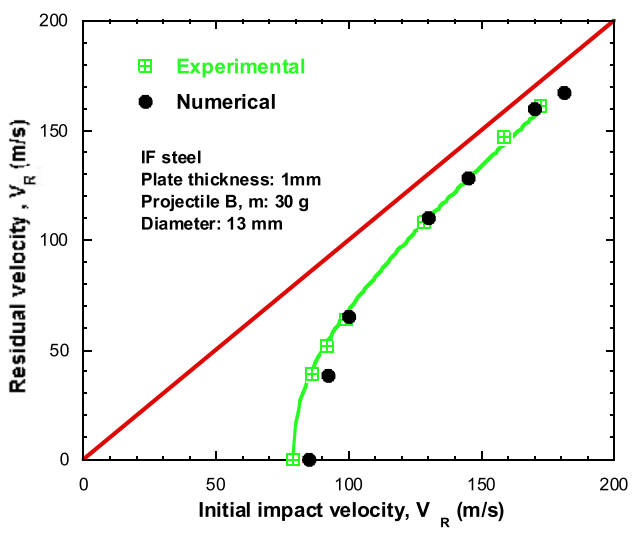

b)

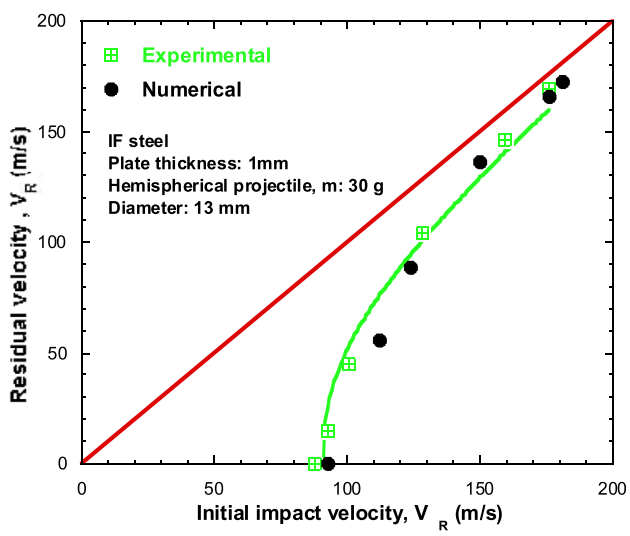

d)

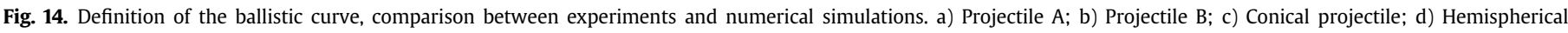
projectile. 
modeled as a three-dimensional deformable body, Fig. 13. The contact between the projectile and the plate was modeled using the penalty method with finite sliding formulation. A constant coefficient of friction $\mu=0.2$ was applied based on experimental studies made by Jankowiak et al. [27] and Rusinek et al. [28]. In order to optimize the mesh, after trying several approaches and taking into account the influence of the element type, the mesh density and the computation time, we chosen to divide the geometry of the plate in two parts: a circular central part of $30 \mathrm{~mm}$ diameter (more than double of the diameter of the projectile, allowing to begin the process of crack propagation accurately without significant effects on the energy balance) and an exterior part that complements the structure to have a rectangular target. The central part of the plate was meshed using C3D8R elements (8-node linear brick, reducing integration with hourglass mode control) available in the Abaqus library [29]. This type of hexahedral element are used with success in nonlinear plasticity analysis $[9,26,28,30,31]$. The effect of hourglass mode is controlled using enhanced method [26] and an optimal mesh. The stability of the results and its mesh size dependence were previously checked $[8,24]$. The aspect ratio of elements was maintained close to unity as recommended by Zukas and Scheffler [32]. A convergence study using a linear hexahedral element in the impact zone with the initial size $\Delta x=\Delta y=\Delta z=0.2 \mathrm{~mm}$ ensures the stability of the numerical solution without mesh sensitivity effect and with optimal time computation. The central part of the numerical model has 110,390 elements ( 5 elements through the thickness of the steel plate). The external part was meshed using C3D8I hexahedral elements (8-node linear brick with incompatible mode). These elements have an additional internal degree of freedom which enhances the ability to model an additional displacement gradient through the element, thereby improving the bending behavior of the structure. The constraints were checked to ensure continuous displacement and stress fields on the border. The size of C3D8I elements used was $\Delta x=\Delta y=\Delta z=0.5 \mathrm{~mm}$ (two elements along the thickness of the steel sheet), leading to a total of 73,640 elements in the external part of the numerical model, Fig. 13.

The material behavior of the IF steel used as a target was incorporated through RK thermoviscoplastic material model described previously (Eq. (2)). Using the flow stress definition provided by the RK relation is possible to particularize the heat equation (Eq. (8)). Thus, the temperature increase is decomposed in two contributions due to the internal stress $\sigma_{\mu}(\varepsilon, \dot{\varepsilon}, T)$ and the effective stress $\sigma^{*}(\dot{\varepsilon}, T)$ :

$$
\left\{\begin{array}{l}
\Delta T=\Delta T_{\text {internal stress }}+\Delta T_{\text {effective stress }} \\
\Delta T=\frac{\beta}{\rho C_{p}} \int_{\varepsilon_{e}}^{\varepsilon_{f}} \frac{E(T)}{E_{0}}\left[\sigma_{\mu}(\varepsilon, \dot{\varepsilon}, T)+\sigma^{*}(\dot{\varepsilon}, T)\right] \mathrm{d} \varepsilon
\end{array}\right.
$$

In order to reproduce the perforation process it is necessary to consider a failure criterion. In this work, the failure criterion used is based on the work by Wierzbicki et al. [33,34] who showed that the equivalent strain at failure expressed as a function of the stress triaxiality would be more appropriate for problems involving fast

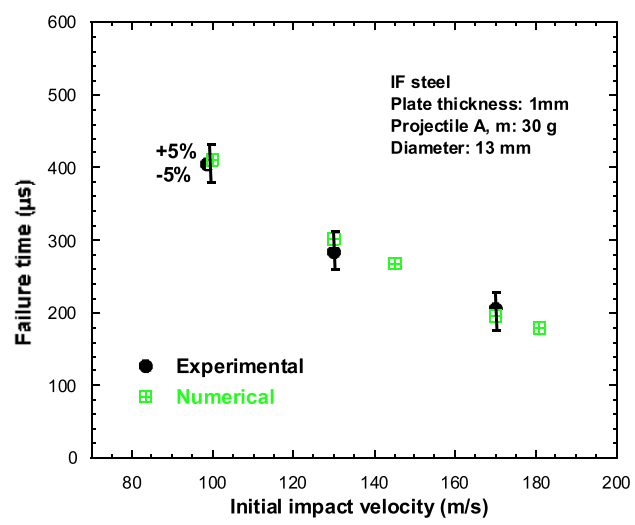

a)

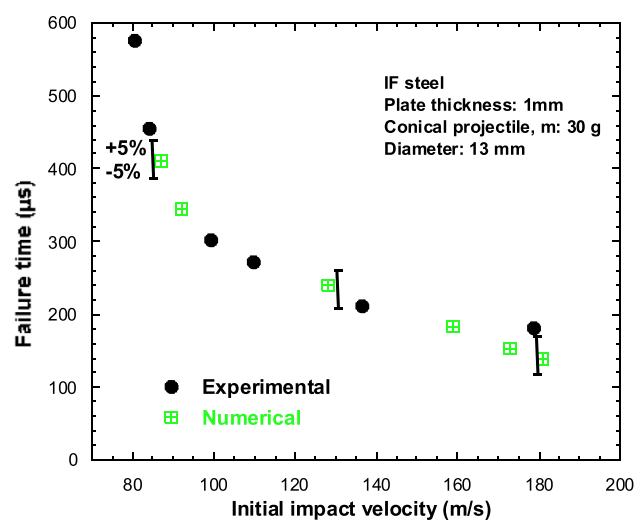

c)

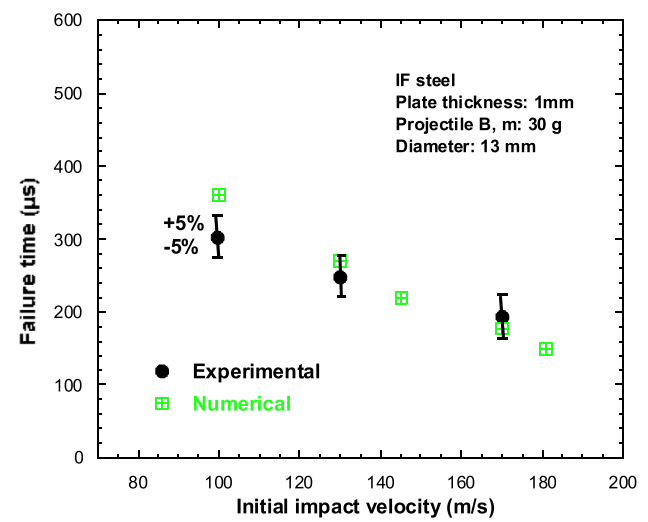

b)

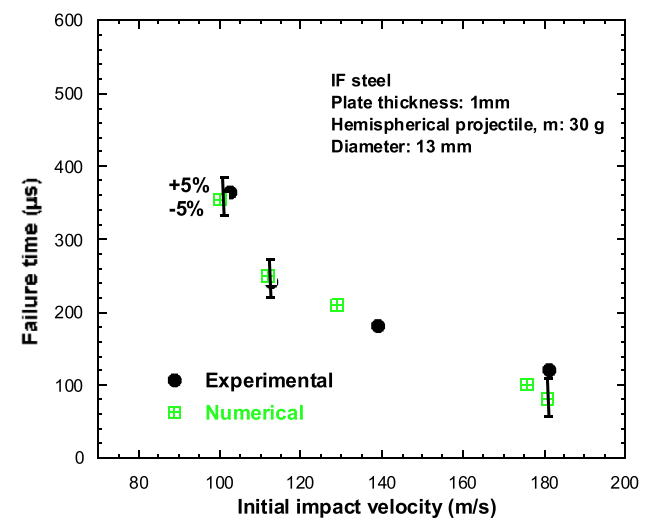

d)

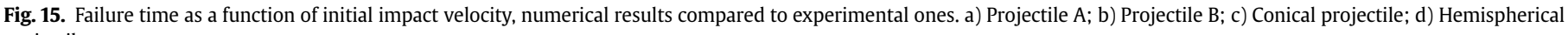
projectile. 
loading. The general form of this type of failure strain can be written as follows:

$\varepsilon_{f}=f(\eta)=f\left(\frac{\sigma_{m}}{\bar{\sigma}}\right)$

where $\varepsilon_{f}$ is the effective plastic strain to failure and $\eta$ is the stress triaxiality defined by the ratio of the mean stress $\sigma_{m}$ to the equivalent stress $\bar{\sigma}$. This kind of fracture model is expressed in the code
Abaqus by erosive criterion inducing instantaneous removal of an element when an imposed plastic strain level is reached in the element. This failure criterion model based on the level of failure strain is often used for dynamic applications [35-37]. The average value of the stress triaxiality can be estimated just before the failure of the target for each projectile studied based on the work of Lee and Wierzbicki [38]. Based on a process of optimization for the whole range of impact velocities considered, the failure strain was estimated depending on the projectile shape, given in Table 4 . The
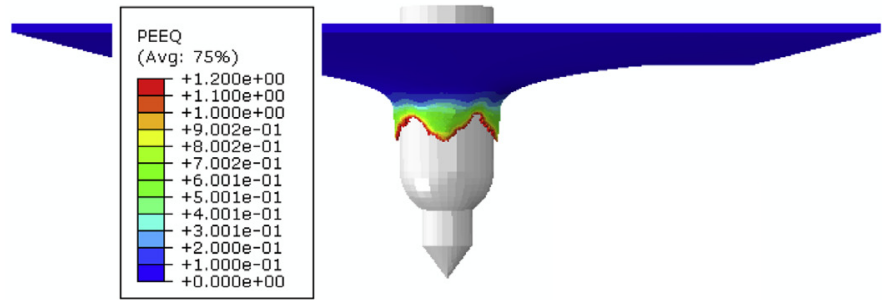

a)
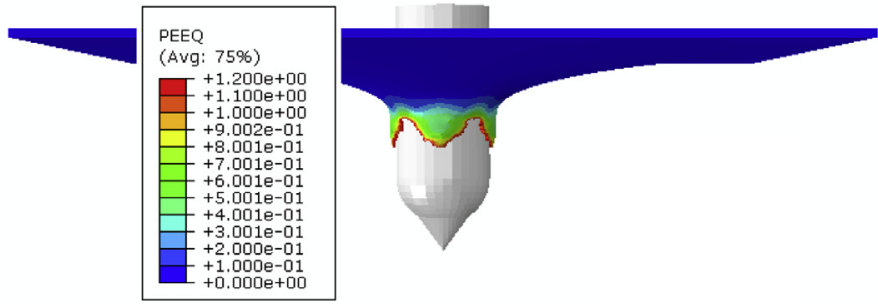

c)
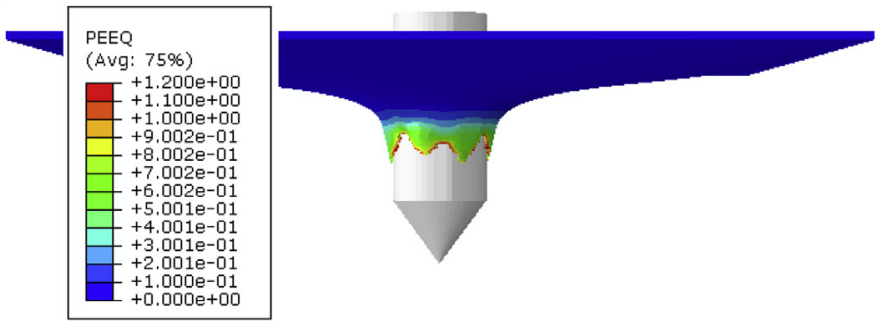

e)

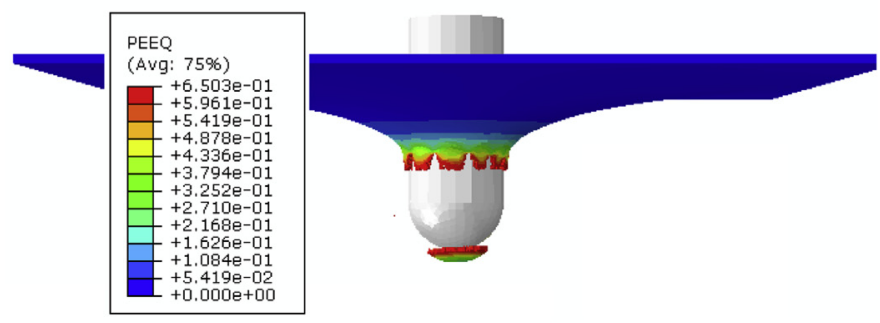

g)

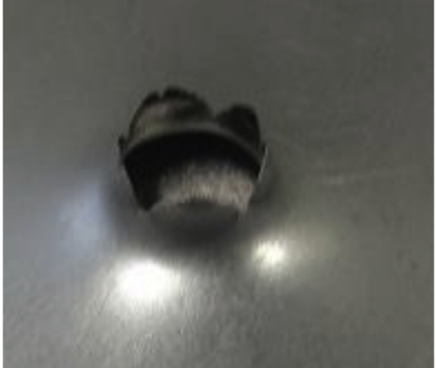

b)

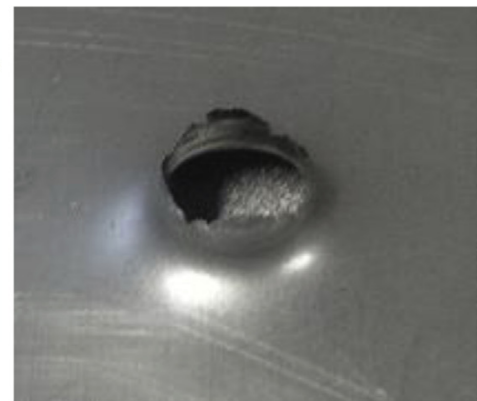

d)

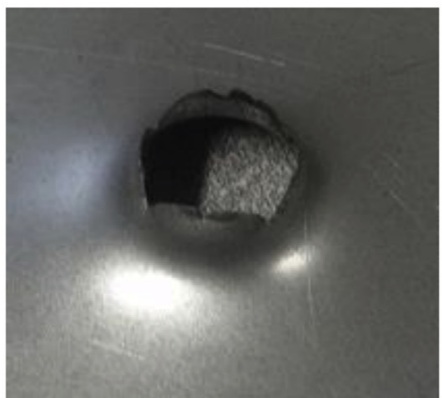

f)

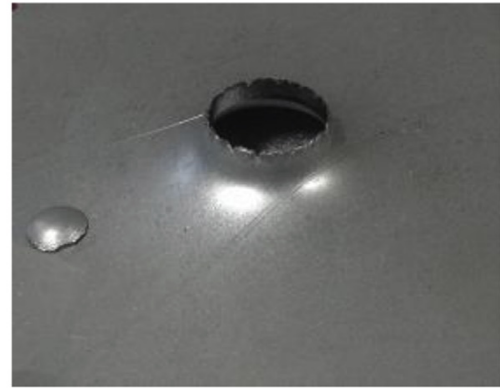

h)

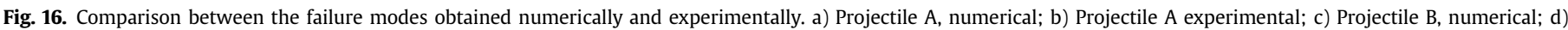

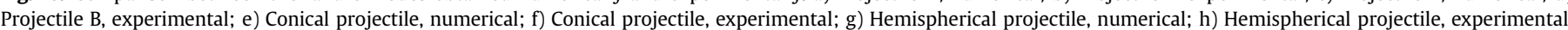


process of numerical optimization was to minimize the error on the residual velocity based on experiments. More details on the optimization process are available in Refs. [9,24].

Numerical simulation were performed for a wide range of initial impact velocities $\left(20 \mathrm{~m} / \mathrm{s} \leq V_{0} \leq 200 \mathrm{~m} / \mathrm{s}\right)$ to cover the range of velocities investigated experimentally, and to provide an accurate and global description of the ballistic curves. All numerical results in terms of ballistic curves, failure modes, the energy absorption balance and failure time are presented and discussed in the next sub-section.

\subsection{Numerical results and discussion}

The results obtained from the numerical predictions in terms of ballistic curves $V_{R}-V_{0}$ are compared to experiments for each projectile and are presented in Fig. 14. A small difference is observed for impact velocities close to the ballistic limit. At impact velocities greater than the ballistic limit $\left(V_{0} \geq 100 \mathrm{~m} / \mathrm{s}\right)$, a good agreement with the experimental results is generally obtained.

Numerical predictions of the ballistic limit velocities are $85 \mathrm{~m} / \mathrm{s}$ for projectile $A, 86 \mathrm{~m} / \mathrm{s}$ for projectile $B, 90 \mathrm{~m} / \mathrm{s}$ for the conical projectile and $93 \mathrm{~m} / \mathrm{s}$ for the hemispherical projectile. The ballistic curves of projectile A and B are almost the same, with their ballistic performance improved by the double nose shape.

The failure time was also estimated numerically using the same definition as in the experiments. The comparison is illustrated in Fig. 15, showing a decreased failure time in increased impact velocity for all shapes of projectiles. This is reasonable because the higher the impact velocity is, the less time the process of perforation takes.

There is a good agreement between the numerical predictions and experiments. The errors are less than $\pm 5 \%$. At a fixed impact velocity, projectile $B$ takes less time than all other projectiles to perforate the plate, followed respectively by the conical projectile, projectile A and the hemispherical projectile.

All failure modes obtained experimentally were reproduced numerically, shown in Fig. 16. Numerical results show a failure mode by petals forming for conical projectile as well as projectiles $\mathrm{A}$ and $B$. For the hemispherical projectile, a plug ejection failure mode was obtained. The petals formed by projectiles A and B are broader, and those by a conical projectile are more pointed. it is also believed that it is the conical nose of the projectiles $A$ and $B$ which governs the failure of the target.

The pictures in Fig. 16 clearly show that the numerical models qualitatively reflect the overall physical behavior of the plate during the impact and perforation. A localization of the plastic strain is noted at the ends of the petals in the case of the conical projectile as well as projectiles $A$ and $B$, but in the zones of the necking for the hemispherical projectile. The maximum equivalent failure strain corresponds to that set by the failure criterion for each projectiles shape.

We also measured the overall deflection of the plate for each projectile shape. The comparison between experimental and numerical results is presented in Fig. 17. The numerical simulation is in perfect agreement with the experiment. The maximum deflection measured is $14 \mathrm{~mm}$ for the case of the conical projectile due to the petals and the minimum is $12 \mathrm{~mm}$ for the hemispherical projectile.

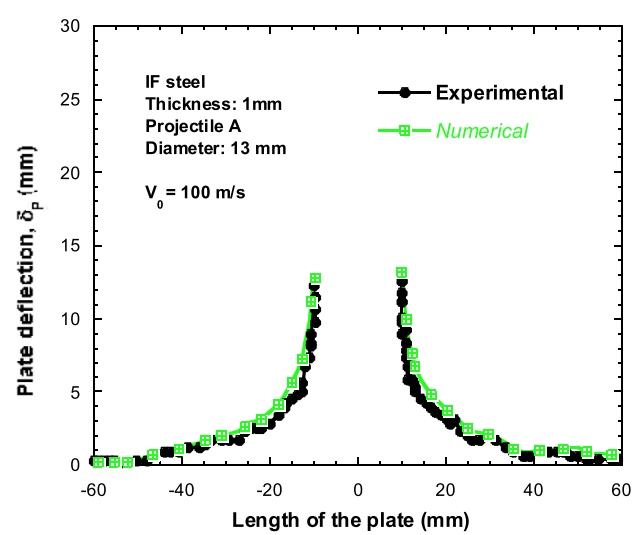

a)

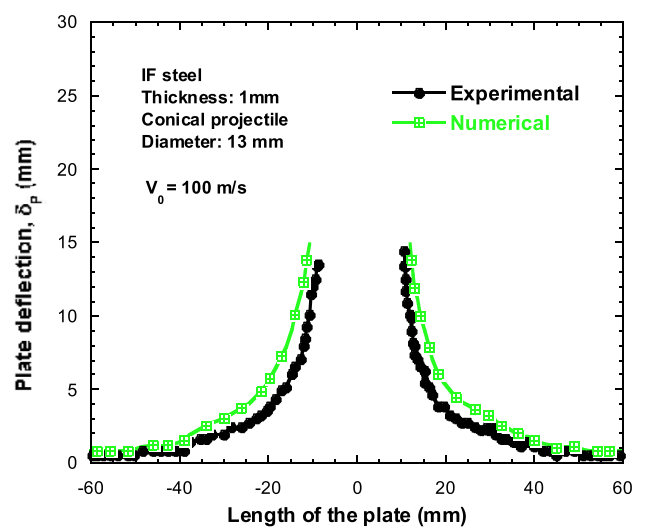

c)

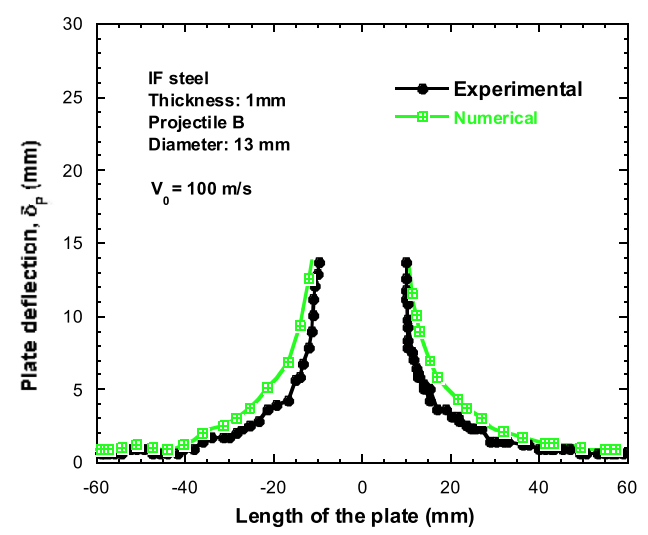

b)

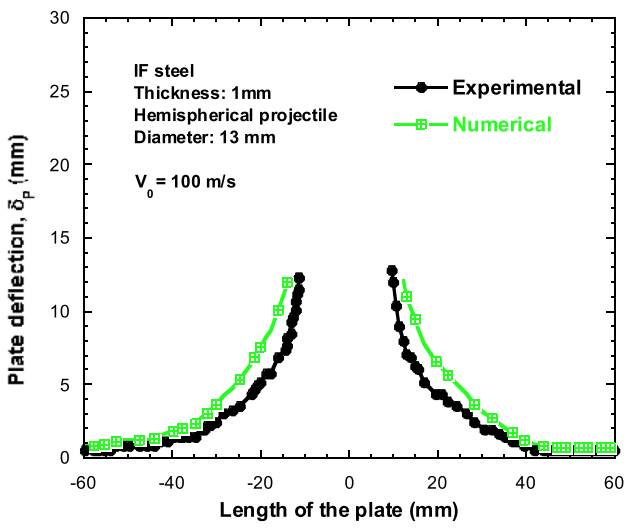

d)

Fig. 17. Global dishing of $1 \mathrm{~mm}$ and $1 \mathrm{~mm}$ thick target. a) Projectile A; b) Projectile B; c) Conical projectile; d) Hemispherical projectile. 
Because the thickness of the plate is low $(1 \mathrm{~mm})$ compared to the diameter of the projectile (13 mm), the deflection of the plate does not change significantly with the impact velocity when it is greater than the ballistic limit.

\section{Conclusions}

Experimental and numerical investigations have been made on an IF steel subjected to impact and perforation loading. Material tests were performed to determine the material constants for the constitutive relation proposed by Rusinek and Klepaczko [1] to take into account the hardening, strain rate and temperature sensitivities. Four different shapes of projectile were considered in this work such as a conical, a hemispherical and two double nose (combination of conical and hemispherical shape) projectile. The ballistic limit for each projectile shape was determined and the ballistic curves plotted. It is found that the ballistic limit, the failure mode and the energy absorption capacity of the target are strongly linked to the projectile nose shape. Energy absorbed by the perforated structure is dissipated by its overall deflection, the elastic deformation and plastic deformation in the localized impact area. The hemispherical projectile is the least efficient to perforate the target followed respectively by the conical projectile, projectile B and $\mathrm{A}$. This observation is confirmed by measuring the failure time of the target using a high speed camera. Indeed, at a giving impact velocity, the projectile A takes less time to perforate the target, followed respectively by projectile $\mathrm{B}$, conical and hemispherical projectile. A numerical analysis of the impact problem has been made using the finite element code ABAQUS/Explicit. The mechanical behavior of the target material has been implemented in the code using the RK constitutive relation. The results obtained from the numerical part were compared to experiments and a good agreement is observe in terms of failure mode, ballistic limit, ballistic curves, energy absorbed by the target and the global deflection of the target.

\section{Acknowledgments}

Authors thank to the National Centre of Research and Development for financial support under the grant WND-DEM-1-203/00.

\section{References}

[1] Rusinek A, Klepaczko JR. Shear testing of a sheet steel at wide range of strain rates and a constitutive relation with strain-rate and temperature dependence of the flow stress. Int J Plast 2001;17:87-115.

[2] Borvik T, Langseth M, Hoperstad OS, Malo KA. Perforation of $12 \mathrm{~mm}$ thick steel plates by $20 \mathrm{~mm}$ diameter projectiles with flat, hemispherical and conical noses part I: experimental study. Int J Impact Eng 2002;27:19-35.

[3] Backman ME, Goldsmith W. The mechanics of penetration of projectiles into targets. Int J Eng Sci 1978;16:1-99.

[4] Corbett GG, Reid SR, Johnson W. Impact loading of plates and shells by freeflyng projectiles: a review. Int J Impact Eng 1996;18:141-230.

[5] Corran RSJ, Shadbolt PJ, Ruiz C. Impact loading of plates: an experimental investigation. Int J Impact Eng 1983:1:3-22.

[6] Goldsmith W, Finnegan AS. Normal and oblique impact of cylindro-conical and cylindrical projectiles on metallic plates. Int J Impact Eng 1986;4:83-105.

[7] Ipson TW, Recht RF. Ballistic perforation by fragments of arbitrary shape, NWC TP 5927. China Lake, CA, USA: Denver Research Institute, Naval Weapons Center; 1977.

[8] Zukas JA. Penetration and perforation of solids. In: Zukas JA, Nicholas T, Swift HF, Greszczuk LB, Curran DR, editors. Impact Dynamics. New York: J. Wiley and Sons; 1982. p. 155-214.

[9] Kpenyigba KM, Jankowiak T, Rusinek A, Pesci R. Influence of projectile shape on dynamic behavior of steel sheet subjected to impact and perforation. Thin Walled Struct 2013:65:93-104.
[10] Borvik T, Langseth M, Hoperstad OS, Malo AK. Perforation of $12 \mathrm{~mm}$ thick stee plates by $20 \mathrm{~mm}$ diameter projectiles with flat, hemispherical and conical noses part II: numerical study. Int J Impact Eng 2002;27:37-64.

[11] Gupta NK, Iqbal MA, Sekhon GS. Effect of projectile nose shape, impact velocity and target thickness on deformation behavior of aluminum plates. Int ] Solids Struct 2007:44:3411-39.

[12] Yunfei D, Wei Z, Yonggang Y, Lizhong S, Gang W. Experimental investigation on the ballistic performance of double-layered plates subjected to impact by projectile of high strength. Int J Impact Eng 2014;70:38-49.

[13] Rusinek A, Cheriguene R, Bäumer A, Larour P. Dynamic behaviour of high strength sheet steel in dynamic tension: experimental and numerical analyses. J Strain Anal Eng Des 2008;43:37-53.

[14] Rusinek A, Zaera R, Klepaczko JR, Cheriguene R. Analysis of inertia and scale effects on dynamic neck formation during tension of sheet steel. Acta Mater 2005; 53:5387-400.

[15] Uenishi A. Teodosiu C. Constitutive modelling of the high strain rate behaviour of interstitial-free steel. Int J Plast 2004;20:915-36.

[16] Klepaczko J. The strain rate behavior of the iron in pure shear. Int J Solid Struct 1969;5:533-48.

[17] Mimura K, Tanimura S. A strain-rate and temperature dependent constitutive model with unified sets of parameters for various metallic materials. In: Kawata K, Shioiri J, editors. IUTAM symp Noda. Japan: Springer; 1995 p. 69-76.

[18] Campbell JD, Ferguson WG. The temperature and strain rate dependence of the shear strength of mild steel. Philos Mag 1970;21:63-82.

[19] Klepaczko JR. A practical stress-strain-strain rate-temperature constitutive relation of the power form. J Mech Work Technol 1987;15:143-65.

[20] Klepaczko JR. A general approach to rate sensitivity and constitutive modeling of FCC and BCC metals. Rotterdam: Impact Eff Fast Transient Loadings; 1988 p. $3-35$.

[21] Rusinek A, Klepaczko JR. Experiments on heat generated during plastic deformation and stored energy for TRIP steels. Mater Des 2009;30:35-48.

[22] Kocks UF, Argon AS, Ashby MF. Thermodynamics and kinetics of slip. Prog Mater Sci 1975:19.

[23] Klepaczko JR, Rusinek A, Rodríguez-Martínez JA, Pęcherski RB, Arias A Modelling of thermo-viscoplastic behaviour of DH-36 and Weldox 460-E structural steels at wide ranges of strain rates and temperatures, comparison of constitutive relations for impact problems. Mech Mater 2009;41:599-621.

[24] Kpenyigba KM. Etude du comportement dynamique et modélisation thermoviscoplastique de nuances d'acier soumises à un impact balistique. université de lorraine [PhD thesis], Lorraine University, Metz, France; 2013.

[25] Recht RF, Ipson TW. Ballistic perforation dynamics. J Appl Mech 1963;30: 384-90.

26] Jankowiak T, Rusinek a, Wood P. A numerical analysis of the dynamic behaviour of sheet steel perforated by a conical projectile under ballistic conditions. Finite Elem Anal Des 2013;65:39-49.

[27] Jankowiak T, Rusinek a, Lodygowski T. Validation of the Klepaczko-Malinowski model for friction correction and recommendations on split Hopkinson pressure bar. Finite Elem Anal Des 2011;47:1191-208.

[28] Rusinek A, Rodriguez-Martinez JA, Zaera C, Klepaczko JR, Arias A, Sauvelet C. Experimental and numerical study on the perforation process of mild stee sheets subjected to perpendicular impact by hemispherical projectiles. Int J Impact Eng 2009;36:565-87.

[29] Abaqus/CAE User's Manuel, Section 17. http://mat1.uibk.ac.at/download/stix/ Abaqus\%206.11\%20Documentation/

[30] Arias A, Rodríguez-Martínez JA, Rusinek A. Numerical simulations of impact behaviour of thin steel plates subjected to cylindrical, conical and hemispherical non-deformable projectiles. Eng Fract Mech 2008;75:1635-56.

[31] Rusinek A, Rodríguez-Martínez JA, Arias A, Klepaczko JR, López-Puente J. Influence of conical projectile diameter on perpendicular impact of thin steel plate. Eng Fract Mech 2008;75:2946-67.

[32] Zukas JA, Scheffer DR. Practical aspects of numerical simulations of dynamic events: effects of meshing. Int J Impact Eng 2000;24:925-45.

[33] Mae H, Teng X, Bai Y, Wierzbicki T. Comparison of ductile fracture properties of aluminum castings: sand mold vs. metal mold. Int J Solids Struct 2008;45: $1430-44$

[34] Wierzbicki T, Bao Y, Lee YW, Bai Y. Calibration and evaluation of seven fracture models. Int J Mech Sci 2005;47:719-43.

[35] Camacho GT, Ortiz M. Adaptive Lagrangian modelling of ballistic penetration of metallic targets. Comput Methods Appl Mech Eng 1997;142:296-301.

[36] Wood WW. Experimental mechanics at velocity extremes - very high strain rates. Exp Mech 1965;5:361-71.

[37] Rodríguez-Martínez JA, Rusinek A, Pesci R, Zaera R. Experimental and numerical analysis of the martensitic transformation in AISI 304 steel sheets subjected to perforation by conical and hemispherical projectiles. Int J Solids Struct 2013:50:339-51.

[38] Lee YW, Wierzbicki T. Fracture prediction of thin plates under localized impulsive loading. Part II: discing and petalling. Int J Impact Eng 2005;31: 1277-308. 